1. Este artigo se baseia na investigação de mestrado de Lisley BraunToniolo, no Programa de Pós-graduação Promoção da Saúde e Prevenção da Violência (FM) da Universidade Federal de Minas Gerais (UFMG), sob orientação de Cristiane de Freitas Cunha e co-orientação de Andréa Máris Campos Guerra. Agradecimento à FAPEMIG pelo financiamento do projeto "O adolescente e a cidade Conversação Clínica: Observatório da Saúde do Adolescente da UFMG e Família Cidadã - BH sem miséria"/ APQ02680-13.

2. Mestra em Promoção da Saúde e Prevenção da Violência pela UFMG, bolsista de pesquisa da Fapemig, psicóloga pela UFES.

e-mail: lisley@gmail.com.

3. Doutora e mestra em Saúde do Adolescente pela UFMG, coordenadora do Eixo Violência do Observatório da Saúde da Criança e do Adolescente, professora do Departamento de Pediatria da FM/UFMG, médica pela UFMG.

e-mail: cristianedefreitascunha@gmail. com.

4. Psicanalista, Doutora em Teoria Psicanalista pela UFRJ, Professora do Programa de Pós-graduação em Psicanálise da FAFICH-UFMG.

E-mail: andreamcguerra@gmail.com

DOI: 10.5752/P.2316-1752.2016v23n32p94 


\title{
CIDADES E FRONTEIRAS: \\ ENTRE EXPANSÃO E FRAGMENTOS ${ }^{1}$
}

CITIES AND BORDERS: BETWEEN EXPANSION AND FRAGMENTS

LAS CIUDADESY FRONTERAS: ENTRE EXPANSIÓNY FRAGMENTOS

\author{
Lisley Braun Toniolo ${ }^{2}$ \\ Cristiane de Freitas Cunha ${ }^{3}$ \\ Andréa Máris Campos Guerra ${ }^{4}$
}

\section{Resumo}

Este artigo objetiva evidenciar os modos como se delimitam as fronteiras na contemporaneidade, tendo em vista o percurso histórico das metrópoles e da urbanização ocidentais, especialmente no Brasil. Discutiremos os efeitos da urbanização capitalista na vivência do espaço atualmente, considerando os fenômenos da segregação e da violência nas cidades brasileiras. Se a metrópole anuncia um campo de possibilidades, verificamos que sua flagrante expansão, ao mesmo tempo em que rompe fronteiras, delimita novos muros, denotando uma vivência desigual e fragmentada da cidade.

Palavras-chave: Cidades. Fronteiras. Violência. Segregação.

\begin{abstract}
This article aims to highlight how the frontiers are delimited in the contemporaneity, considering the historical course of the metropolis and the western urbanization, especially in Brazil. We discuss the effects of capitalist urbanization on the experience of the space nowadays, contemplating the phenomenon of segregation and violence in Brazilian cities. If the city announces a field of possibilities, we find that it's flagrant expansion, at the same time that breaks boundaries, delimits new walls, showing an uneven and fragmented experience of the city.
\end{abstract}

Keywords: Cities. Borders. Violence. Segregation.

\section{Resumen}

Este artículo intenta evidenciar las formas en que se fijaron las fronteras en la contemporaneidad, teniendo en cuenta el curso histórico de la metrópolis y la urbanización occidental, especialmente en Brasil. Vamos a discutir los efectos de la urbanización capitalista en la experiencia del espacio actual, considerando la segregación y la violencia en las ciudades brasileñas. Si la ciudad anuncia un campo de posibilidades, verificamos que su expansión flagrante, mientras que rompe fronteras, delimita nuevos muros, denotando una experiencia desigual y fragmentada de la ciudad.

Palabras clave: Ciudades. Fronteras. Violencia. Segregación. 


\section{Introdução}

A violência nas grandes cidades ocupa uma das principais pautas brasileiras na contemporaneidade, o que podemos constatar, por exemplo, na expressividade dos dados estatísticos na área da saúde, no bombardeamento midiático no qual estamos imersos, na paisagem urbana, que não esconde aqueles que estão à margem da cidade e da cidadania. Cotidianamente, deparamo-nos com ruas esvaziadas após certo horário da noite, praças pouco ocupadas, muros altos, câmeras de segurança por toda parte, uma preocupação constante com nossos pertences, o estado de alerta contra o possível mal a nos invadir. Verificamos que recentemente a violência ${ }^{5}$ passou a ser considerada como um agravo à saúde, constituindo a principal causa de óbitos na faixa-etária entre 15 e 29 anos. Constatamos, no "Mapa da violência 2014: os jovens do Brasil", que, entre todos os óbitos ocorridos na população jovem no país, 71,7\% foram decorrentes da violência. Tal expressividade, contudo, é atrelada a uma parcela específica da população: os jovens negros. Temos que, entre 2002 e 2012, a taxa de homicídios de jovens negros sofreu aumento de $32,4 \%$, considerando negros aqueles que se declaram pardos e pretos. Se, em 2002, morreram proporcionalmente $73 \%$ mais negros que brancos, já em 2012, essa taxa aumentou para $146,5 \%$. Nesse período, a vitimização negra cresceu $100,7 \%$, tanto pela diminuição dos homicídios na parcela jovem branca quanto pelo aumento destes em relação aos jovens negros (WAISELFISZ, 2014).

Se, por um lado, as grandes cidades brasileiras representam um campo aberto de possibilidades, atraindo pessoas de todos os confins do País, por outro, a vida urbana não se mostra acolhedora a todos, como pudemos brevemente constatar. Holston (2013), ao analisar o desenvolvimento da cidadania brasileira, considera perverso o paradoxo da democratização do País, uma vez que, ao lado das inovações democráticas vivenciadas, temos o aumento de novos tipos de violência, injustiça, corrupção e impunidade.

É justamente esse paradoxo que pretendemos analisar neste artigo, visando a retomar algumas experiências ocidentais de cidade, desde a Revolução Industrial inglesa, até chegarmos às metrópoles brasileiras na contemporaneidade. Esse percurso será realizado tendo em vista as vivências espaciais das fronteiras modernas e contemporâneas, a fim de elucidar como as cidades brasileiras, hoje sem bordas, difusas, expandidas, protagonizam tamanha segregação e violência.

A retomada histórica é nosso fio condutor, para podermos registrar os elementos que possibilitaram os arranjos atuais, as relações entre territórios, entre pessoas, o corpo que a cidade constitui, tendo em vista a demolição e reconstituição cotidiana de fronteiras. Advertidos de que não podemos tomar a cidade como entidade única, a ser reproduzida de maneira homogênea nos diversos espaços onde se materializa, buscamos, nesta revisão de literatura, articular tanto os aspectos globais das cidades contemporâneas quanto aquilo que é mais singular na constituição e na vida das metrópoles brasileiras.
5. Referimo-nos aos óbitos por causas externas, constituídos por acidentes de trânsito, suicídios e homicídios. No item "A cor da violência nas cidades brasileiras", outros dados serão mais detalhadamente apresentados. 


\section{Linhas, fronteiras, percursos}

\section{As grandes cidades ocidentais}

A urbanização das cidades ocidentais, como nos esclarece Zucconi (2001), intensifica-se na Europa, no século XIX, após a Revolução Industrial. Esse processo é marcado por uma expansão ilimitada que se concentrou nas cidades existentes na época, ou, ainda, criou novas cidades onde não havia nada. Para o autor, os elementos considerados decisivos ao surgimento das grandes cidades foram a concentração do excedente demográfico, os fluxos migratórios e o consequente nivelamento da população rural e urbana. Para além da industrialização, os antigos centros comerciais, as estradas pré-existentes e a malha ferroviária constituíram também fatores cruciais para o surgimento dessas grandes cidades.

A ferrovia inaugurou a possibilidade de criar uma rede de relações à longa distância. São os nós ferroviários, industriais e portuários que passam a concentrar os excedentes demográficos, que se devem também à melhoria das condições de vida na Europa à época. Entre 1850 e 1914, ocorreu o primeiro período de expansão da cidade rumo à metrópole: "O século XIX corresponde à fase de transição entre um antigo regime, marcado por delimitações férreas, e a plena atuação do princípio segundo o qual os homens e os produtos podem circular livremente" (ZUCCONI, 2001, p. 36). Para Henri Lefebvre (1999, p. 61), a cidade "universaliza a concorrência, transforma todo capital em capital industrial, acelera a circulação e a centralização desses capitais". A liberdade requerida para a nova cidade faz com que as antigas muralhas caiam em desuso e sejam ressignificadas: demolidas, contornadas por anéis rodoviários. "Associada à queda do limite urbano, a demolição das muralhas marca de modo espetacular a passagem entre idade moderna e contemporânea" (ZUCCONI, 2001, p. 37, grifo do autor). A muralha representava uma fronteira precisa entre o dentro e o fora. A nova cidade passou a prescindir de fronteiras visíveis. As demarcações tradicionais foram refeitas: o fora, antes excluído, assimilou a expansão e a nova vida da cidade. O movimento tomou o lugar da estática fronteira: "Até então a cidade constituía um mundo próprio, que a extinção dos limites colocou dramaticamente frente à própria diversidade" (ZUCCONI, 2001, p. 34).

A diversidade e a extinção da fronteira como representante do limite convocam uma nova identidade para a cidade urbana. A produção de fronteiras invisíveis busca demarcar novamente a relação do dentro com o fora, dos diferentes. A diversidade que o urbano colateralmente assimilou produz um questionamento contínuo sobre o limite que, mesmo não podendo ser visto, será construído coletivamente e individualmente nas histórias das cidades e de suas populações. É necessário compreender, assim, como o fenômeno urbano produziu questões sociais que materializam novas fronteiras, com as quais lidamos também em nosso cotidiano.

Cadernos de Arquitetura e Urbanismo, v.23, n.32, $1^{0}$ sem. 2016 


\section{A cidade estranha}

A nova identidade da cidade urbana ocidental começou a se delinear em Paris e em Londres. O exemplo de Paris chama atenção, por ter sido realizado a partir de um planejamento urbano e de um modo de operar a relação Estado-cidade que repercutiu mundialmente, tendo profundo impacto no que será a cidade do século XX (ZUCCONI, 2001). Napoleão III conferiu ao Barão de Haussmann a atribuição de remodelar Paris, tendo este sido prefeito do Sena de 1853 a 1870 (ZUCCONI, 2001). O redesenho deveria partir de uma malha que interligasse os pontos importantes da cidade e os novos marcos funcionais da capital, ou seja, havia uma necessidade premente em conciliar o novo e o velho, inscrever o presente, passado e futuro em um só território. Haussmann planejou sua obra em três fases, que são denominadas réseaux (redes), e tinham por objetivo solucionar os problemas de circulação já existentes na época (ZUCCONI, 2001). De acordo com Zucconi (2001), o primeiro réseau (1855) contemplou a demolição de quadras residenciais para a construção de prédios públicos. O segundo réseau (1858) apoiou-se na construção de novos eixos para a circulação, inaugurando os grandes bulevares parisienses. O terceiro réseau, por sua vez, consistiu na maior alteração realizada, fazendo com que Paris absorvesse uma nova faixa entre os dois traçados das muralhas existentes. "Assim, ele faz com que Paris se torne uma cidade estranha para os próprios parisienses. Não se sentem mais em casa nela. Começa-se a tomar consciência do caráter desumano da grande metrópole" (BENJAMIN, 1985, p. 41). O modelo de "haussmanização" envolveu o rearranjo completo dos fluxos da cidade. A inauguração de grandes prédios públicos, os grands travaux, fez com que novos problemas devessem ser solucionados, como a questão do esgoto, das águas, o tráfego viário e ferroviário, escolas, hospitais, entre outros. Haussmann remodelou a estrutura funcional da cidade (ZUCCONI, 2001). Além da implantação de novas redes físicas para fluxos de pessoas, implementou uma rede econômica que foi primordialmente o que se transmitiu de seu trabalho: no momento em que o Estado não teria condições financeiras de arcar com toda a remodelagem da cidade, abriu-se o investimento e financiamento de capital privado, criou-se um fluxo contínuo de capital que alimentava a dívida pública e dava cada vez mais lugar aos interesses privados nas decisões estatais. Inaugurou-se, assim, um sistema contínuo de investimento de capital privado nas obras públicas do Estado.

É importante notar como os elementos que demarcavam a nova cidade tornavam-se outros: em vez de muralhas, eram os fluxos e redes que passariam a delimitar as novas fronteiras. Ao mesmo tempo em que o planejamento e a remodelação das cidades estimulavam o desenvolvimento tecnológico e, consequentemente, melhoravam as condições de vida na grande cidade, especialmente no que diz respeito às patologias e salubridade, eram novos os problemas que acompanhavam tal reconfiguração.

A relação do sujeito com o espaço nas grandes cidades passou a dizer respeito à saúde, uma vez que se tornou neces- 
sário zelar cada vez mais pela força de trabalho, bem como proteger os países das epidemias propagadas diante da alta concentração de pessoas. No texto "O nascimento da Medicina Social", Foucault (1979) retoma as origens da relação da saúde com a esfera coletiva, e os sentidos que essa união tinha à época, no final do século XVIII. O autor distingue três etapas para o desenvolvimento da Medicina Social: a Medicina de Estado (começo do século XVIII), a Medicina urbana (final do século XVIII) e a Medicina da força de trabalho (segundo terço do século XIX).

Em linhas gerais, a Medicina de Estado se constituiu na Alemanha, inaugurando as primeiras estatísticas de natalidade e mortalidade dos países, tendo origem uma prática médica que objetivou a melhoria das condições de saúde de sua população. A Medicina urbana nasceu na França, tornando-se uma Medicina da cidade, voltada a combater o medo urbano (FOUCAULT, 1979). Tal iniciativa fez frente à constituição de tensões internas entre a burguesia e um novo proletariado que, concentrado em Paris, passou a se articular para lutar por seus direitos. Somados a isso, os novos elementos urbanos provocaram angústia e receio aos habitantes, que passaram a se deparar com a modificação acelerada da paisagem urbana, por meio de crescentes instalações de fábricas, aumento vertiginoso da população, a invasão de epidemias urbanas, a expansão da cidade e dos cemitérios, a constituição do esgoto subterrâneo, entre outros fenômenos que atravessaram o século XIX (FOUCAULT, 1979; ZUCCONI, 2001). A Medicina urbana se apoia na prática da quarentena, ou seja, no internamento do doente dentro da cidade e de seus dispositivos, em sua vigilância e monitoramento constante, o que foi auxiliado pelo esquadrinhamento de bairros e de novas redes de comunicação. Assim, a Medicina urbana encontra três grandes objetivos: analisar possíveis locais que provoquem doenças, o controle da circulação da água e do ar, e, finalmente, a reorganização dos diferentes elementos conflitantes na cidade: por exemplo, água potável e esgoto. As grandes avenidas se justificavam para manter a saúde da população (FOUCAULT, 1979).

Ressaltamos a relação entre o desenvolvimento da saúde pública e da cidade urbana, que se cruzam, dialogam. Os locais tidos como passíveis de produção de doença eram, além dos cemitérios e matadouros, evidentemente os bairros pobres habitados pelo proletariado: "É colocada no centro da pesquisa, mais do que outras, a questão dos slums, termo inglês que designa áreas de degradação social e edilícia" (ZUCCONI, 2001, p. 75). A grande cidade foi medicalizada (FOUCAULT, 1979): "Conseguindo mudar o quadro que faz fundo às patologias, o mal é cortado pela raiz" (ZUCCONI, 2001, p. 84). Trata-se de uma Medicina das coisas, e não propriamente dos indivíduos, que introduz consigo a noção de salubridade (FOUCAULT, 1979). Fica claro como a Medicina urbana influenciou o desenvolvimento das redes planejadas por Haussmann. Várias medidas urbanas foram tomadas para tornar a cidade mais salubre, o que não possibilitou, porém, a extinção da angústia e do medo de viver em grandes cidades. 
$\mathrm{Na}$ Inglaterra, então, surgiu a Medicina dos pobres (do proletariado) (FOUCAULT, 1979). Se a Medicina urbana francesa se detinha sobre os lugares de amontoamento, confusão e perigo, foi a Medicina inglesa que se deteve sobre o pobre como indivíduo. A partir desse momento, a noção de perigo atravessou a noção de pobreza, unidas por uma crise habitacional que mal acabara de nascer e se estenderia até os dias atuais. A pesquisa estatística teve origem na saúde, a fim de localizar o mal com precisão, ao mesmo tempo em que objetivava comparar contextos diferentes (ZUCCONI, 2001). O controle da saúde dos pobres era, em última instância, o controle do proletariado, a garantia da saúde para trabalhar e para que não oferecessem riscos à burguesia.

Como vimos, novas disciplinas e tecnologias do saber foram criadas para dar conta do fenômeno urbano. Ao mesmo tempo, o papel social da Igreja era diminuído conforme o Estado entrava em cena, e outras instituições como escolas, bibliotecas, centros cívicos ou comerciais tomaram seu lugar de agregação de sujeitos, formando a noção de bairro (ZUCCONI, 2001). A vida começou a se organizar em prol das cidades a que tivemos acesso dentro de uma mesma cidade, daquilo que é ofertado como bairro, como entorno. O mercado liberal, apoiado na especulação imobiliária, forneceu os elementos cruciais que levaram as cidades a expandir cada vez mais. Terrenos anteriormente agrícolas passaram a valer como terrenos edificáveis, e o impulso da expansão urbana tendeu a se propagar com base na demanda crescente por habitações (ZUCCONI, 2001). Lefebvre (1999) pontua, baseado em Engels, que as cidades inglesas eram marcadas por um verdadeiro empiIhamento de trabalhadores para suprir as demandas industriais e que o ritmo de remodelação das cidades para a construção de novas habitações, bem como os baixos salários, já inaugurava uma crise habitacional intencional, na qual a especulação imobiliária teve lugar privilegiado. A cidade, em seu interior, encontrou-se com vários fenômenos. O impulso à expansão permanece, e novas fronteiras se desenvolvem a partir das redes e fluxos criados: o medo, a angústia e a segregação se agravam entre pobres e ricos. É nesse contexto que se desenvolvem as primeiras metrópoles.

\section{A metrópole no século vinte ${ }^{6}$}

O ponto de partida para a formação das metrópoles se deu entre 1850 e 1914, na transição dos séculos XIX e XX. A metrópole é marcada pelas disparidades resultantes do capitalismo. "A máquina urbana tinha se revelado um instrumento de exclusão, segregação e empobrecimento de qualquer experiência para grande parte de sua população" (SECCHI, 2009, p. 33). É o lugar, por excelência, onde o trabalhador se vê dissociado da sua força de trabalho e daquilo que produz (LEFEBVRE, 1999). Lefebvre (1999) elucida que a força do ser se volta contra ele como um monstro animado e nos questiona se a cidade não seria a encarnação desse monstro. A metrópole, esse monstro animado, capturada nessa metáfora, dialoga também com a perspectiva de Milton Santos, quando distingue os usos que as pessoas fartas de recurso fazem da cidade toda, em de-
6. Século vinte é escrito por extenso como no título do livro de Bernardo Zucconi: "A cidade do século vinte".

Cadernos de Arquitetura e Urbanismo, v.23, n.32, $1^{0}$ sem. 2016 
trimento do uso parcial daqueles a quem faltam meios, e a vivenciam "como se fosse uma pequena cidade" (SANTOS, 2002, p. 140). O trabalhador anima a cidade com sua força de trabalho. Com a vida que injeta na estaticidade dos imóveis, produz o dinamismo do mercado, das articulações entre pessoas e bairros.

Essa cidade que transborda sobre si e sobre o outro caracteriza a metrópole, e, nesse transbordamento, ela escapa à dimensão de toda. Seja devido às distinções no acesso à cidade de acordo com a classe social, mudando a amplitude do todo, seja pela sua expansão acelerada e contínua, que torna as fronteiras cada vez mais confusas. Assim, como Milton Santos (2002, p. 140) constatou, "a rede urbana, o sistema de cidades, também tem significados diversos segundo a posição financeira do indivíduo". Não que a condição financeira seja a única forma de inscrição do sujeito na sociedade e no território, mas sim que, a partir dela, outras vivências e modos de existir inscrevem subjetividades no espaço social. Nesse sentido, Zucconi (2001, p. 58) complementa que "a própria ideia de metrópole está baseada na ideia do contraponto entre cenários contrastantes e situações extremas que passam do extremo da excepcionalidade aos abismos do vício". O século vinte constituiu-se como o palco das metrópoles, que se afirmara no mundo ocidental como modelo de cidade, desenvolvendo-se de maneira sem precedentes (SECCHI, 2009).

Secchi (2009) acrescenta que tal desenvolvimento é marcado por uma aceleração acentuada do movimento das coisas, informações, pessoas e, ao mesmo tempo, por relações impessoais e instáveis. A população mundial é redistribuída ao longo do século, havendo maciço abandono das áreas rurais em prol da cidade na América e na Ásia, enquanto na Europa houve um estancamento da concentração urbana. A cidade se forma, então, por agregações diversas que se encontram e disputam em torno da conquista do poder e da hegemonia, do modo de saber fazer com o território. Disso decorre a impossibilidade de interpretá-la como antes, estando a sociedade urbana dispersa e disseminada em estilos de vida inumeráveis, difusos (SECCHI, 2009). Entre suas novas características, destacam-se autonomia do sujeito, a construção da noção de privacidade que acompanha a ideia de isolamento, o cotidiano como dimensão privilegiada de uso do tempo e do espaço, onde se poderia alcançar o bem-estar social e individual. A individualização do uso do espaço urbano ganha força, centralizando-se na relação do indivíduo com a cidade. Essa nova cidade é "luminosa, inodora e lavável" (SECCHI, 2009, p. 177), busca, por meio do padrão, dos imperativos do consumo e da ciência, reconstruir-se diante do vazio que ela mesma constitui.

Os fenômenos urbanos denotam as formas e políticas de produção desse vazio, majoritariamente econômicas. No século vinte, alguns fenômenos se sobressaem, como a dispersão, a verticalização e a recente gentrificação. A dispersão remete à expansão horizontalizada da cidade, feita de maneira difusa, confundindo as fronteiras entre territórios e cidades já demarcadas. A dispersão é o crescimento sem limites e, por isso, coloca-nos questões aparentemente contraditórias, como a 
não finitude do espaço e a ameaça da dissolução da cidade. Conforme as tecnologias se desenvolvem e permitem novos meios de deslocamento, surgem as periferias, "o produto mais evidente do crescimento urbano" (SECCHI, 2009, p. 36), claramente atreladas ao fenômeno da dispersão. A verticalização, como o nome indica, é a expansão vertical, o aumento da concentração de pessoas e atividades em áreas de intensa dinâmica, ocorrendo principalmente nas áreas centrais das cidades. A concentração advinda da verticalização ameaça a sociedade a ser "reduzida a uma multidão indiferenciada" (SECCHI, 2009, p. 34). A gentrificação, por sua vez, remete à reocupação e revitalização de áreas (geralmente centrais) outrora abandonadas pela classe média e alta, acompanhada pela especulação imobiliária. Juntos, esses fenômenos constituem o modelo americano de metrópole que influencia todos os demais continentes (SECCHI, 2009).

De acordo com Secchi (2009), o aumento da concentração junto à dispersão da cidade provoca angústia e medo na população. A vida na cidade é tomada pelo insuportável, e problemas como mobilidade e segurança pública viram pautas do cotidiano. A instabilidade marca a metrópole diante da impossibilidade de se constituir como um todo. A cidade é sem borda. Ao mesmo tempo, a cidade do século vinte foi considerada por toda uma geração de intelectuais como parte de um projeto ampliado para reconstruir a sociedade, principalmente após a Primeira Guerra Mundial. O intuito era rever as relações do homem com o espaço, o que refletiria diretamente nas relações dos homens entre si. Para tanto, políticas para a cidade foram desenhadas, visando a alcançar o bem-estar social e a liberdade. Liberdade de ir e vir, de projetar e reconstruir a cidade, repensá-la, acessá-la. Em última instância, projetar o bem-estar e a liberdade seriam formas de contornar a noção que também se instalou no século vinte da cidade como metáfora do destino do indivíduo e da sociedade (SECCHI, 2009).

Um destino que é revestido de aridez. "Em relação ao passado, a cidade se tornou uma máquina de produção e, ao mesmo tempo, de integração, mas também de exclusão e segregação ainda mais poderosa" (SECCHI, 2009, p. 35). Ainda que crie possibilidades, o espaço urbano também promove impossibilidades, sendo as regiões urbanas os cenários que mais evidenciam as desigualdades sociais no mundo. Em 2010, a ONU (UNITED NATIONS, 2015) estimou que 830 milhões de pessoas vivem em slums, termo utilizado para se referir aos lugares onde se imagina que as atividades clandestinas ocorram com frequência, relacionados a partes da cidade que são habitadas por populações pobres (SECCHI, 2009). Em paralelo, outro signo da desigualdade se faz presente, as famosas gated communities, condomínios fechados nos quais parte da população se isola do convívio com os demais, especialmente com os pobres.

A organização espacial das metrópoles, ainda que porte elementos de influência local, parece responder a uma mesma lógica no Ocidente, na qual há o rompimento de fronteiras diante da dispersão e, ao mesmo tempo, a proliferação de novas formas de marcar e vivenciar divisões internas, seja na 
pluralidade de modos e estilos de vida encontrados, seja nas distintas possibilidades de acesso à cidade. Nessa pluralidade, ainda reproduzimos padrões arcaicos de nos relacionarmos em sociedade, muitas vezes pautados na dominação e exclusão. As concepções que marcam a cidade do século vinte dialogam com o monstro animado, encarnando ameaças como o destino, a indiferenciação, a exclusão e a dispersão rumo ao desaparecimento. Ameaças que se consolidam nas relações sociais e atingem o espaço e sua delimitação.

\section{Pós-metrópole: segregação e fragmentação espacial}

Para Edward Soja (2008), a metrópole já não se apresenta da mesma forma que outrora. Retomando diversos autores e suas análises sobre fenômenos da urbanização contemporânea, o autor trabalha a ideia de pós-metrópole. Entre suas marcas, podemos incluir a globalização, uma expansão de mercado que transcende as cidades, acelerada após o declínio do welfare state e a progressiva retração do Estado como mediador das relações econômicas e sociais. Pela globalização "o mundo é introduzido na zona simbólica em cada cidade" (SOJA, 2008, p. 223, tradução nossa)7. Esse mundo remete não somente a transformações econômicas, mas também a impactos culturais (a cultura de massa, que faz a torsão de cidadãos em consumidores), políticos-ideológicos e sociais. Mundialmente, poucas cidades situam-se como protagonistas na organização do espaço e dos interesses, definindo as relações socioeconômicas e espaciais nos demais países (MONTE-MÓR, 2006).

A partir da crise do modelo de bem-estar social, agravada na década de 1960, as tensões internas da cidade urbano-industrial levaram a uma fragmentação cada vez maior da cidade. Tal fragmentação é vivenciada em várias esferas, tanto na organização residencial quanto nas divisões do governo local, das classes sociais, raças e etnias, evocando uma separação crescente. Nesse cenário, a metrópole é redesenhada, dando origem à pós-metrópole, que contempla a variação das questões reestruturadoras advindas da crise e da desigualdade, (re) modelando os espaços urbanos (SOJA, 2008).

Soja (2008) caracteriza a pós-metrópole como o lugar onde imaginário e real se misturam. Nela, a cidade real não existe sem a cidade imaginada, uma vez que seus contornos são difusos, frequentemente delimitados na relação do um a um com o espaço, e também no encontro conflituoso das diversas classes sociais e minorias. Trata-se de uma metamorfose parcial e incompleta, que guarda em si os restos da metrópole, ao mesmo tempo em que se torna algo completamente novo. A mudança radical está naquilo que a cidade representa, abandonando o lugar de entidade autônoma e bem definida, passando a estar cada vez menos ligada à sua determinação espacial. O que mudou? "A cidade como um ponto fixo de referência, memória e identidade coletiva" (SOJA, 2008, p. 221, tradução nossa) ${ }^{8}$. Nessa transformação, a paisagem pós-metropolitana se tornou repleta de distintos tipos de espaços protegidos e fortificados, que pretendem isolar os perigos reais e imaginá-
7. [...] el mundo (y el espacio más allá) es introducido en la zona simbólica de cada ciudad.

8. [...] la ciudad como un punto fijo de referencia, memoria e identidad colectiva.

Cadernos de Arquitetura e Urbanismo, v.23, n.32, $1^{0}$ sem. 2016 
rios da vida cotidiana. A cidade fortaleza (DAVIS, 1990) é retomada sob uma nova lógica: o inimigo é sempre imaginário e, sem muralhas, ele pode estar ao lado. Essa cidade se anuncia pela formação de ilhas urbanas visíveis e nem tão visíveis. São erigidos sinais invisíveis que proíbem o acesso a lugares pseudopúblicos (SOJA, 2008), uma vez que a destruição do espaço público é crescente e a segmentação do que resta é evidente. Soja (2008) também denomina essa nova cidade de arquipélago carcerário, onde a crescente fragmentação da cidade é acompanhada de um forte apelo por segurança, o que transformaria os espaços sociais em novas roupagens das antigas prisões. A cidade fortaleza combina desenho urbano, arquitetura e aparato policial (DAVIS, 1990; SOJA, 2008).

Entre as ilhas (in)visíveis, podemos situar os condomínios fechados, as favelas, os bairros étnicos, as ruas fechadas. Para Davis (1990) e Soja (2008), as cidades fortaleza são nitidamente divididas em celas fortificadas para os ricos e lugares de terror nos quais a polícia luta contra os pobres, considerados criminosos. Bauman (2009, p. 40) indica que "paradoxalmente, as cidades - que na origem foram construídas para dar segurança a todos os seus habitantes - hoje estão cada vez mais associadas ao perigo". Ele propõe que tal associação tenha se originado a partir da redução do controle estatal. Com Bernardo Secchi, ficamos atentos ao fato de que "mudando a natureza daquele que provoca medo, muda a retórica da segurança e principalmente mudam os mecanismos dispostos para debelar o medo" (SECCHI, 2009, p. 63). Novos argumentos de segurança são lançados a partir do momento em que a retração da intervenção estatal lança muitos indivíduos à própria sorte. Além disso, Bauman (2009) pontua que o medo e a insegurança são vetores para obtenção de grandes lucros comerciais, como o comércio de armas, câmeras de vigilância, cercas elétricas e demais aparatos de segurança. Entregues ao neoliberalismo, as cidades são profundamente atravessadas pelos interesses do capital. E essa é uma ótica importante para observarmos o fenômeno contemporâneo da vigilância, esteja ela presente nas câmeras e olhos vivos espalhados na cidade ou manifesta nos programas televisivos que tudo veem. A vigilância e seus dispositivos são tomados por Bauman (2013) como dimensão-chave do mundo atual: câmeras de vídeo, escâneres corporais, checagem biométrica, compras on-line, entre outros exemplos. A figura máxima desse olho que tudo vê é encarnada nos smartphones, dispositivos que nos permitem transportar sobre nossos corpos os panópticos pessoais e garantir um funcionamento ininterrupto, seja do dispositivo, seja do indivíduo, que nunca podem desligar (BAUMAN, 2013).

A vigilância, a cidade fortaleza e o arquipélago carcerário ilustram o que se denomina guerra social, substituindo o velho paradigma liberal que conciliava repressão e reforma. Naquele paradigma, havia certa disjunção entre a guerra e o social, sendo a primeira voltada para fora, e o social voltado para dentro (DAVIS, 1990; SOJA, 2008). Hoje, o social é tratado a partir da repressão, como evocam as manifestações a favor da redução da maioridade penal no Brasil, por exemplo. A guerra social contribui para o acirramento da segregação na 
vida urbana, uma vez que o inimigo passa a ser interno. A arquitetura urbana contemporânea inaugura novas formas de operar a segregação, como podemos notar a partir de suas fortalezas, dos arquipélagos carcerários, shoppings centers, muros e cercas nas residências, câmeras por todos os lados (SOJA, 2008). As minorias étnicas, os problemas sociais, a pobreza e os pobres passam a ser olhados por um viés majoritariamente repressivo. Em nosso país, essas cenas se repetem, à sua maneira.

\section{A urbanização chega ao Brasil}

A constituição de um Brasil urbano não se deve ao acaso. Talvez possamos até mesmo falar em "Brasis" urbanos, quando percebemos as distintas realidades regionais neste País de dimensões continentais. As muralhas se disseminam na história brasileira por meio das diversas desigualdades insistentes que dão consistência às fronteiras (in)visíveis que erigimos em nossas relações com o outro e com o espaço. As primeiras cidades brasileiras tiveram origem no Recôncavo Baiano e na Zona da Mata do Nordeste (SANTOS, 2009), no Brasil colonial (1500 a 1822). "Ao fim do período, a rede urbana estava constituída por respeitável conjunto de 63 vilas e 8 cidades" (SANTOS, 2009, p. 20). Milton Santos (2009) nos elucida que os elementos que impulsionaram a urbanização brasileira já nesse período foram tanto a organização político-administrativa do Brasil colonial, marcada pelas capitanias e o governo-geral, quanto as atividades econômicas rurais voltadas para exportação e subsistência. O governo-geral (15481808) bem como as atividades de exportação e de troca para subsistência tinham sede nas cidades e vilas coloniais. Até esse período, as cidades tinham uma vida intermitente, ou seja, não havia uma dinâmica contínua de fluxos de mercadoria e pessoas, sendo a dinâmica urbana determinada pela sazonalidade da agricultura. No fim do século XIX, a transição do engenho para a usina foi primordial para a valorização do capital financeiro em detrimento do capital que a terra representava, provocando a primeira aceleração do fenômeno urbano: a taxa de urbanização brasileira passou de 5,9\% em 1872 para 9,4\% em 1900. Já entre 1920 e 1940, a população urbana no Brasil triplicou (SANTOS, 2009).

Contudo, ainda nessa época, não havia uma integração do território nacional. A dinamicidade do território brasileiro aprimorou-se a partir da implantação de estradas de ferro, melhoria dos portos, implantação de meios de comunicação, concentrando-se inicialmente no Sudeste, em torno de cidades-polo, como São Paulo e Rio de Janeiro. A industrialização se iniciou nessa região, em uma primeira fase que se estende até 1930. Entre 1940 e 1950, a industrialização do País viveu novo impulso, assumindo-se como um processo social complexo que envolvia a criação de um mercado nacional, a integração do território e a expansão do consumo, sendo decisiva no processo de urbanização brasileira. Em 1940, a taxa de urbanização brasileira era $26,35 \%$, passando a 68,86\% em 1980. Na década de 1950, o Brasil vivenciou uma revolução demográfica marcada pelo aumento da natalidade e diminuição das taxas 
de mortalidade. Já na década de 1960, houve uma inflexão no aumento da população urbana. Entre 1970 e 1980, a urbanização foi novamente acelerada (SANTOS, 2009).

James Holston ilustra a metropolização brasileira a partir da cidade de São Paulo, cujo "frenético crescimento [...] começou na década de 1890 com o início da industrialização e o influxo de imigrantes estrangeiros" (HOLSTON, 2013, p. 210). Retomando os movimentos migratórios, Holston (2013) remonta as origens da concentração populacional na formação das grandes cidades brasileiras, marcadamente constituída pelos "flagelados" nordestinos, que fugiam da seca na década de 1920, e os imigrantes europeus, que buscavam na recente indústria uma alternativa ao trabalho agrícola. A partir das migrações e da industrialização das grandes cidades, "fábricas, estradas de ferro e serviços industriais apareceram quase da noite para o dia em muitas áreas da cidade [...] nas proximidades dos centros comercial e residencial" (HOLSTON, 2013, p. 210). São Paulo tornou-se uma típica cidade industrial, "uma confusão concentrada de funções, classes, nacionalidades, raças e espaços" (HOLSTON, 2013, p. 211).

A expansão da urbanização brasileira para além da faixa litorânea ocorreu após a década de 1970, diante dos processos de macrourbanização e metropolização (SANTOS, 2009). As grandes cidades brasileiras tiveram crescimento espraiado, devido ao tamanho desmesurado produtor e produto de especulação. Milton Santos divide o País entre o Brasil urbano e o agrícola, arranjos que substituem a antiga divisão entre rural e urbano. "Nas regiões agrícolas, é o campo que, sobretudo, comanda a vida econômica e social do sistema urbano [...], enquanto nas regiões urbanas são as atividades secundárias e terciárias que têm esse papel" (SANTOS, 2009, p. 76, grifo do autor). O que não implica dizer que não haja cidades nas regiões agrícolas e ruralidade nas grandes cidades, mas que a organização política e econômica desses espaços é distinta. Para o autor, os avanços técnicos e científicos, principalmente a biotecnologia, permitiram a expansão das cidades no Brasil, inaugurando plantações de soja, por exemplo, onde antes só havia cerrado. A partir da expansão agrícola, fruto de um capitalismo já amadurecido, “há acentuada especialização de tarefas no território, [...] que é tanto mais sutil quanto necessária porque essas produções não são um dado puramente técnico: toda produção é técnica, mas também socioeconômica" (SANTOS, 2009, p. 43).

Assim, no início da década de 1990, formaram-se regiões de modernização concentrada (estados do Sul, São Paulo e Rio de Janeiro, principalmente), havendo no restante do País uma modernização seletiva: "O espaço se torna mais articulado às relações funcionais, e mais desarticulado quanto ao comando local das ações que nele se exercem" (SANTOS, 2009, p. 49). A modernização é fenômeno crescente no Brasil. Seja no campo, seja na metrópole, a expansão do capital envolve a substituição maciça da mão de obra pelo uso da tecnologia, e a consequente urbanização do território. No processo de urbanização brasileira e na história de suas metrópoles, não podemos deixar de notar o surgimento e a expansão crescente das periferias como espaço de exclusão e segregação social. 


\section{As cidades não oficiais}

Para Holston (2013, p. 209), a periferia é "um espaço emaranhado na amargura de uma expulsão, de segregação, de ilegalidade e do heroísmo de dominação e redefinição". O autor localiza na Independência do País o agravamento das disparidades sociais, uma vez que o Brasil República foi instituído mediante ideias de tendência liberal e conservadora, não havendo qualquer menção a tratar a igualdade social como questão a ser perseguida. Além disso, a vivência de quatro séculos de escravidão de índios e negros afetou profundamente a noção de cidadania, uma vez que estes eram tratados como mercadoria, não sendo contemplados como cidadãos. Apenas após a Abolição da Escravatura a cidadania foi ampliada aos ex-escravos, contudo de maneira bastante desigual. Holston caracteriza o Estado brasileiro como um "desajeitado Estado" (HOLSTON, 2013, p. 101). Nesse sentido, o autor elucida, desde a colonização portuguesa, as tentativas atrapalhadas de um governo em se fazer presente nacionalmente, neste país enorme, apoiado nos poderes locais das elites, o que culminou na manutenção de um Estado com base em dispositivos ilegais (milícias, coronelismo). Ou seja, o Estado delegava às elites locais sua representação nos confins brasileiros, e estas se apoiavam em formas ilegais para manutenção do seu próprio poder, o que se tornou a forma mais comum de se relacionar com o Estado burocrático e controlador: burlando-o. As arbitrariedades locais e a hegemonia dos coronéis, conforme o Governo brasileiro se expandia, foram transpostas também para as organizações estatais e municipais.

O Brasil teve, a partir de então, uma relação com a terra profundamente marcada pelos interesses dessas elites locais, que se tornaram também os interesses do Estado. Em 2000, $1,7 \%$ da população brasileira era dona de quase $50 \%$ das terras aráveis no País (HOLSTON, 2013). Foi diante da queda da atividade escrava e da importação de mão de obra europeia que o Estado brasileiro passou a dispor de suas terras como mercadoria, operando a lógica da especulação imobiliária. A estratégia adotada envolvia preços da terra altos e salários baixos, impedindo que esses trabalhadores tivessem acesso legal à propriedade, forçando com que se submetessem a trabalhos semisservis (HOLSTON, 2013, p. 259). É nítido, então, que a terra se tornou um privilégio das elites brasileiras, não sendo considerada como um direito da população. Nesse contexto, Valladares (2000) explicita que as primeiras formas de os pobres ocuparem a cidade moderna se restringiram à construção de cortiços centrais e favelas, perto dos locais de trabalho, e, mais tarde, nas periferias. Os cortiços representavam a concentração dos trabalhadores e dos denominados vadios e malandros na cidade, sendo considerados o lugar da pobreza no século XIX. Após serem categorizados como espaços propícios ao vício e ao contágio de doenças, no Rio de Janeiro, os cortiços foram duramente combatidos a partir da reforma urbana do prefeito Pereira Passos, no período entre 1902 e 1906 (VALLADARES, 2000).

As primeiras favelas no Rio de Janeiro foram constituídas por imigrantes, ex-combatentes de Canudos e pelas populações 
despejadas das áreas centrais (antigos cortiços). A informalidade marca a ocupação do solo, assim como a omissão do Estado desde o primeiro momento. As burocracias para construir, somadas à pobreza, à ausência de políticas públicas de moradia, saneamento básico, entre outros fatores, tornaram a favela, desde seu início, "uma nova categoria para designar as aglomerações pobres, de ocupação ilegal e irregular, geralmente localizadas em encostas" (VALLADARES, 2000, p. 7). Para a autora, o termo favela remete a dois aspectos complementares: a resistência e o perigo, pois, no momento em que os moradores da favela se fazem conhecer pela sua resistência, solidariedade e capacidade de sobreviver à tamanha miséria, essa força resistente se torna uma ameaça à elite urbana, caso se articule para tomar seu lugar na cidade. A favela passa a ser alvo de combate, sendo que o Código de Obras do Distrito Federal de 1937, artigo 349, proíbe explicitamente sua construção (VALLADARES, 2000).

Além dos cortiços e favelas, a urbanização brasileira, tal como se deu, ainda teve como efeito a periferização da pobreza: "o desenvolvimento das periferias urbanas e a institucionalização dos direitos sociais fundados no trabalho urbano consolidaram um padrão centrífugo de segregação nas cidades brasileiras e modernizaram a já diferenciada cidadania dos brasileiros" (HOLSTON, 2013, p. 197).

É interessante observar a expressão "padrão centrífugo", que consiste no afastamento dos pobres do centro das cidades, do lugar que concentra os poderes políticos e econômicos. O crescimento das regiões metropolitanas é, dessa forma, marcadamente acentuado pela periferização do território, provocando a expansão da cidade a áreas que não têm condições prévias para habitação, o que ocorreu incialmente diante da expulsão e dissolução dos cortiços nos centros das grandes cidades, como São Paulo e Rio de Janeiro (HOLSTON, 2013; VALLADARES, 2000). Podemos observar, contudo, que os lócus da pobreza na cidade não são estáticos, nem são dados a priori. Tanto os cortiços quanto as favelas e periferias estão sempre em mutação, apoiados na autoconstrução e nas redes de solidariedade que substituem ali o papel do Estado. Trata-se de movimentos de resistência ao não lugar que é dado, uma forma de entrar no circuito, ocupar a cidade.

Longe de glamorizar a pobreza, a ideia é tampouco a de vitimizar o pobre, mas de estarmos atentos aos ecos e respostas dos processos de urbanização brasileiros. É preciso tomar a periferia não como objeto de intervenção, mas como um coletivo que inventa modos de viver, apesar dos lugares que (não) Ihes são dados. Essas invenções, quando escutadas, apontam direções importantes e mais autênticas do que a simplória ideia do perigo, da criminalização da pobreza, da vitimização.

\section{Ecos da pós-metrópole no Brasil}

Os ecos da pós-metrópole se fazem ouvir também no Brasil, o que podemos melhor evidenciar com alguns autores brasileiros. Milton Santos (2002) já nos alertava sobre a cidade não toda, ou seja, uma cidade que não se realiza por completo para aquele que não dispõe de recursos para percorrê-la. Essa ci- 
dade, contudo, tornou-se impalpável e inalcançável também para os ricos, no momento em que as fortalezas substituíram os espaços de convivência que existiam. O perigo ameaça o ir e vir, a segregação entra em cena. Se até a década de 1980 os grandes fluxos migratórios no Brasil constituíam pano de fundo para a segregação vivenciada nas cidades, a partir da década de 1990, outros fatores se sobressaíram nesse campo, dados pelo

Cruzamento entre as forças operantes no mercado de terras e a especulação imobiliária, a fragilização dos vínculos de trabalho e encolhimento de alternativas de emprego, e outros tantos que vêm de uma história já antiga de ausência ou precariedade de políticas habitacionais (TELLES, 2006, p. 59).

As realidades urbanas brasileiras se complexificam, e o entrecruzamento dos fatores citados por Telles acirra a vivência das desigualdades sociais. A modernização seletiva fragmenta cada vez mais o território nacional, ao passo que os espaços urbanos excluídos desse circuito "são crescentemente atravessados por ilegalismos de todos os tipos, para não falar da violência e seus impactos disruptivos nas sociabilidades cotidianas" (TELLES, 2006, p. 44). Uma nova cartografia da pobreza se configura (TELLES, 2006), culminando na redelimitação constante do que se considera ou não como cidade. Maricato (2000) nos ilustra tal processo quando pensa a favela como um lugar que não participa da cidade oficial: seja nos procedimentos de coleta do IBGE, seja em sua estrutura pré-moderna de planejamento, e também por não se encaixar no mercado imobiliário formal. Entre as consequências da exclusão territorial, destacam-se a predação ambiental e o aumento da violência (MARICATO, 2000). As periferias autoconstruídas, as favelas, as ocupações, são os principais representantes desses territórios marginais à cidade.

A violência é associada à cidade, em um primeiro momento, sendo atrelada aos espaços excluídos dos mapas da cidade oficial. Ao mesmo tempo em que essa própria exclusão territorial pode ser vivida como uma violência, torna-se também um signo das diversas exclusões vivenciadas pelos pobres e demais minorias nas cidades brasileiras. Há, então, uma dissimetria marcante entre as integrações políticas, econômicas e culturais, principalmente dos jovens moradores dos bairros pauperizados (TELLES, 2006). A lógica do mercado não reconhece fronteiras, pelo contrário, ele as utiliza como convém. A assimilação do consumo como valor de identidade percorre "todos os cantos", como bem disse Vera Telles (2006). As dinâmicas de exclusão se complexificam, assim como o (não) lugar dos pobres na cidade e no circuito capitalista. Trata-se de uma realidade dinâmica, fluida e desafiadora.

No curso de suas vidas, indivíduos e suas famílias atravessam espaços sociais diversos, seus percursos passam por diversas fronteiras, e são esses traçados que podem nos informar sobre a tessitura do mundo urbano, seus bloqueios, suas fraturas, pontos de tensão (TELLES, 2006, p. 52). 
Esses pontos de tensão surgem na mídia cotidianamente, ilustrados sob a perspectiva do medo e do terror, colorindo os noticiários policiais, econômicos e políticos. A pós-metrópole conjuga uma pluralidade de oportunidades, serviços, lugares, que, ao contrário do que aparentam, não são a todos acessíveis. Telles (2006) nos chama a atenção para nos aproximarmos do contemporâneo no Brasil investigando a linha de sombra que atravessa a cidade, articulando a sedução e os encantos do mercado de consumo e o bloqueio de oportunidades no mercado de trabalho, a contraposição de práticas lícitas e ilícitas, bem como sua capilaridade nas tramas da sociabilidade popular.

Alerta-nos ainda que a lógica binária da exclusão-inclusão, centro-periferia, não mais responde ao que se apresenta no cenário atual, no qual se desenham "novas fronteiras sociais e territoriais, legais e políticas, seguindo os traços das mudanças engendradas pelos circuitos globalizados da economia urbana, bem como pelas redefinições dos modos de governo da cidade e seus espaços" (TELLES, 2015, p. 16). Nesse contexto, os contornos territoriais se apresentam incertos, havendo campos de tensões e conflitos disseminados por toda parte, resultantes da fricção entre a mercantilização dos espaços e das formas de vida, e a lógica do controle militarizado na gestão dos territórios urbanos (TELLES, 2015). Recentemente, para além da guerra social voltada às periferias e ao abuso de poder estatal contra seus moradores, a desmedida repressão policial mostra sua face diante dos insurgentes que manifestam contra a privatização crescente das cidades, seja clamando pelo direito à mobilidade, seja para denunciar os próprios excessos policiais e estatais.

A atualidade urbana brasileira é marcada, assim, pela lógica da especulação imobiliária, comumente composta por remoções forçadas e revitalização de áreas geralmente ocupadas por populações marginalizadas, o que recentemente foi evidenciado com as obras voltadas à Copa de 2014 e às Olimpíadas de 2016. Mais do que preparar as cidades para receber os eventos mundiais, há uma intenção acentuadamente mercadológica em torno das ações governamentais, com os serviços que daí decorrem, bem como os já conhecidos favorecimentos das elites. Ao mesmo tempo, as periferias brasileiras vivem, ao lado dos ideais de pacificação por parte do Estado e de sua polícia, a expansão do mercado como proposta de inclusão social, em ações que pretensamente trabalham para o fortalecimento local, quando, na verdade, tratam a questão da pobreza como possibilidade de empreendedorismo (TELLES, 2015). Esse modo de atuar nas periferias, ao contrário de reduzir ou redimensionar as fronteiras existentes, acaba por resumir um problema marcadamente social (e, portanto, estatal) a um problema de mercado (privado), privilegiando iniciativas individualistas em prol de ações coletivas que poderiam reinventar práticas territoriais e sua ligação com o restante da cidade. A paisagem urbana brasileira acentua tal realidade, a qual materializa cotidianamente, na falta de infraestrutura e mobilidade urbana em várias áreas marginalizadas, na proliferação de condomínios fechados, shoppings centers, equipamentos de se- 


\section{Conclusão}

Percebemos, na atualidade, uma cidade complexa, dispersa e, ao mesmo tempo, ainda voltada para as centralidades econômicas. Novos contornos são estabelecidos continuamente, em um ritmo acelerado, caminhando uma expansão que supõe a própria dissolução da ideia de cidade. A pós-metrópole se desenha fragmentada, ao mesmo tempo pautada por determinações mundiais, prioritariamente mercadológicas, advindas dos países de primeiro mundo. A urbanização brasileira, diante disso, mostra-se em compasso com as tendências mundiais, principalmente se nos apoiarmos em suas grandes cidades, mas também denuncia uma modernização incompleta e excludente (MARICATO, 2000), fator que acirra as desigualdades no País. Imersos na desigualdade, na ausência de limites e no transbordamento de muros entre as pessoas, percebemos que a cidade não se assume mais como um todo, composta por um dentro e um fora. Ao contrário, as espessas linhas que ainda separam as pessoas, prioritariamente econômicas, desenham-se de maneira capilar, constituindo circuitos muitas vezes invisíveis onde se deslocam e se afirmam as desigualdades. As fronteiras são pautadas em uma urbanização cuja perspectiva é mercadológica e não cidadã. Disso decorrem os dados apresentados em nossa introdução, onde evidenciávamos a dimensão do problema da violência em nossas cidades. Jovens negros são assassinados diariamente, denunciando a aspereza da vida nas grandes cidades brasileiras, principalmente para aqueles que não estão formalmente inclusos no mercado de trabalho, ainda que muitas vezes nem tenham idade para tal.

A pós-metrópole se abre em cidades, em campo de possibilidades, lugares e não lugares. Ela comporta, contudo, sempre um mal-estar: "a metrópole tem este atrativo adicional - que mediante o que se tornou pode-se recordar com saudades daquilo que foi" (CALVINO, 1990, p. 30). Os avanços da civilização, ao contrário do que sonhamos, não nos garantiram uma vida segura e isenta de sofrimento. Ao retomarmos a história da cidade urbano industrial no mundo e em nosso País, pudemos observar como as fronteiras se estabelecem a partir de uma outra perspectiva, relegando os problemas sociais à repressão, pela via da segregação e da retórica do medo, que nos fazem deslocar a violência presente nessas linhas invisíveis aos fenômenos que observamos diariamente nos jornais. Lefebvre (2001, p. 22) nos alerta para os conflitos inerentes à vida urbana, que "pressupõe encontros, confrontos das diferenças, conhecimentos e reconhecimentos recíprocos". É preciso ir além de uma cidade dividida para recompor as possibilidades do urbano, no inédito que somente o encontro pode propiciar, nas brechas, na insurgência. Não se trata de abolir o conflito, pois a segregação é justamente isso, a recusa à diferença. Mas sim de interrogarmos as muralhas que erigimos nas formas mais sutis de uso do espaço, 
de relacionamento, de exercício da cidadania e do consumo. O urbano e sua expansão também propiciam uma enorme gama de possibilidades de invenção, e é a partir de suas fissuras e fragmentos que devemos atuar. Não para negá-los, mas para que possamos lançar outros desenhos à cartografia que pulsa nas veias das incontáveis cidades invisíveis.

\section{Referências}

BAUMAN, Zygmunt. Confiança e medo na cidade. Rio de Janeiro: Jorge Zahar, 2009.

BAUMAN, Zygmunt. Vigilância líquida. Rio de Janeiro: Jorge Zahar, 2013.

BENJAMIN, Walter. Paris, capital do século XIX. In: KOHTE, Flavio (org). Walter Benjamin. São Paulo: Ática, 1985, p. 31-43.

CALVINO, Italo. As cidades invisíveis. 2. ed. São Paulo: Companhia das Letras, 1990.

DAVIS, Mike. City of Quartz: excavating the future of Los Angeles. Nova lorque: Verso, 1990.

FOUCAULT, Michel. O nascimento da medicina social. In: FOUCAULT, Michel. Microfísica do poder. Rio de Janeiro: Graal, 1979, p. 79-98.

HOLSTON, James. Cidadania insurgente. São Paulo: Companhia das Letras, 2013.

LEFEBVRE, Henri. A cidade do capital. Rio de Janeiro: DP\&A, 1999.

LEFEBVRE, Henri. O direito à cidade. São Paulo: Centauro, 2001.

MARICATO, Ermínia. O lugar fora das ideias e as ideias fora de lugar: planejamento urbano no Brasil. In: ARANTES, Otília; VAINER, Carlos; MARICATO, Ermínia (orgs.) A cidade do pensamento único: desmanchando consensos. 3. ed. Petrópolis: Vozes, 2000, p. 121-192.

MONTE-MOR, Roberto Luís de Melo. O que é o urbano no mundo contemporâneo. Revista Paranaense de Desenvolvimento, Curitiba, n. 111, p. 9-18, jul./dez. 2006. Disponível em: <http://www.academia.edu/9911631/O_QUE_\%C3\%89_O_ URBANO_NO_MUNDO_CONTEMPOR\%C3\%82NEO>. Acesso em: 10 dez. 2014.

SANTOS, Milton. A urbanização brasileira. São Paulo: EDUSP, 2009.

SANTOS, Milton. O espaço do cidadão. 7. ed. São Paulo: EDUSP, 2002.

SECCHI, Bernardo. A cidade do século vinte. São Paulo: Perspectiva, 2009. (Debates Urbanismo.)

SOJA, Edward William. Postmetrópolis: estudios críticos sobre las ciudades y las regions. Madrid: Traficantes de Sueños, 2008.

TELLES, Vera da Silva. Cidade: produção de espaços, formas 
de controle e conflitos. Revista de Ciências Sociais, Fortaleza, v. 46, n. 1, p. 15-41, jan./jun., 2015.

TELLES, Vera da Silva. Debates: a cidade como questão. In: TELLES, Vera da Silva; CABANES, Robert (orgs.). Nas tramas da cidade: trajetórias urbanas e seus territórios. São Paulo: Humanitas, 2006, p. 35-64.

UNITED NATIONS. Over 200 million escape slums but overall number still rising, UN report finds. In: UN News Centre, 18 mar. 2010. Disponível em: <http://www.un.org/apps/news/ story.asp? NewsID=34119\#.U-vmDYBdW_M>. Acesso em: 10 nov. 2015.

VALLADARES, Lícia do Prado. A gênese da favela carioca: a produção anterior às Ciências Sociais. Revista Brasileira de Ciências da Saúde, João Pessoa, v. 15, n. 44, p. 5-26, out. 2000.

WAISELFISZ, J. J. Mapa da Violência 2014: crianças e adolescentes do Brasil. Rio de Janeiro: Centro Brasileiro de Estudos Latino-Americanos, 2014.

ZUCCONI, Guido. A cidade do século XIX. São Paulo: Perspectiva, 2001. (Debates Urbanismo.)

Recebido em 30/11/2015

Aprovado em 25/04/2016 